\title{
Effect of Interaction between SDS and Tween 80 on Nucleation Behavior of Electrodeposited Copper Powder
}

\author{
Shuzhi Diao ${ }^{1}$, Yiyong Wang ${ }^{2, *}$, Hui Jin ${ }^{3}$, Jidong Lit ${ }^{4}$ Xianglin Liu ${ }^{5}$ \\ ${ }^{1}$ School of Materials \& Metallurgy, University of Science and Technology Liaoning, Anshan 114051, \\ China \\ ${ }^{2}$ School of Materials \& Metallurgy, University of Science and Technology Liaoning, Anshan 114051, \\ China \\ ${ }^{3}$ School of Materials \& Metallurgy, University of Science and Technology Liaoning, Anshan 114051, \\ China \\ ${ }^{4}$ School of Materials \& Metallurgy, University of Science and Technology Liaoning, Anshan 114051, \\ China \\ ${ }^{5}$ School of Materials \& Metallurgy, University of Science and Technology Liaoning, Anshan 114051, \\ China \\ *E-mail: wangyiyongfly@ 163.com
}

doi: $10.20964 / 2020.12 .53$

Received: 8 January 2020 / Accepted: 14 August 2020 / Published: 31 October 2020

To study the electrochemical behavior of surfactants (sodium dodecyl sulfate (SDS) and Tween 80) during the deposition process, the electrocrystallization mechanism of copper powder was determined. Electrochemical test methods, such as linear sweep voltammetry (LSV), chronoamperometry (CA), and electrochemical impedance spectroscopy (EIS), were used. The kinetic parameters of the deposition process were calculated by the fitting experimental curves to verify the correctness of the theoretical analysis. The results show that the electrocrystallization process of copper conforms to the ScharifkerHills 3D nucleation/growth mechanism. When the concentration of the surfactant was $0.2 \mathrm{~g} / \mathrm{L}$ SDS+0.1 $\mathrm{g} / \mathrm{L}$ Tween 80 , the surfactant with a chain composite structure shifted the deposition potential negatively and increased the cathode polarization. The electrocrystallization of copper in the potential region from $-0.20 \mathrm{~V}$ to $-0.22 \mathrm{~V}$ was consistent with gradual nucleation, with a prolonged nucleation relaxation time and decreased nucleation rate. When the concentration of the surfactant was $0.8 \mathrm{~g} / \mathrm{L} \mathrm{SDS}+0.1 \mathrm{~g} / \mathrm{L}$ Tween 80 , the composite structure of the surfactant changed from long chains to spherical micelles. The spherical micelles positively shifted the deposition potential of copper and decreased the cathode polarization. Copper electrocrystallization in the potential region of $-0.20 \mathrm{~V}$ to $-0.22 \mathrm{~V}$ was consistent with instantaneous nucleation, the nucleation relaxation time was reduced, and the nucleation rate was accelerated. EIS showed that the surfactant Tween 80 formed a resistive film on the cathode surface. When $0.2 \mathrm{~g} / \mathrm{L}$ SDS was added, the resistance $\mathrm{R}_{1}$ of the resistive film increased; when SDS increased to $0.8 \mathrm{~g} / \mathrm{L}$, spherical micelles formed. Holes appeared in the resistive film, and its resistance decreased. 
Keywords: Chronoamperometry; kinetic parameters; spherical micelles; resistance film

\section{FULL TEXT}

(C) 2020 The Authors. Published by ESG (www.electrochemsci.org). This article is an open access article distributed under the terms and conditions of the Creative Commons Attribution license (http://creativecommons.org/licenses/by/4.0/). 